\title{
Editorial: The Behavior of Organizations in a Scalable Selectionist System
}

\author{
Donald A. Hantula ${ }^{1}$
}

Published online: 17 June 2019

(C) Association for Behavior Analysis International 2019

A 50-year mark puts things in context and perspective. As this issue goes to press we look back to half a century ago and observe some things that changed our world. In 1969, popular culture gave us 3 days of peace and music at Woodstock, while "The Brady Bunch," "Monty Python's Flying Circus," and "Sesame Street" debuted on TV. WalMart was incorporated, and in time would change the retail landscape. The Stonewall riots occurred, ushering in the movement for LGBTQ rights. In science, B. F. Skinner was presented with the President's National Medal of Science, and we saw the beginnings of the internet when the initial ARPANET link was established. The first 747 took off and Neil Armstrong walked on the moon, each accomplished with less computing power than exists in a present-day mobile phone. This issue's target article reviewing 50 years of research and application in the Teaching Family Model (TFM) should occasion some reflection; about behavior science, behavior analysis and attempts to address social problems. In particular, why did it work, why it has lasted?

The short answer is: that which replicates and adapts endures. Fitting with this year's prior issue of $P o B S$ that focused on replication (Branch, 2019; Hales, Wesselmann, \& Hilgard, 2019; Laraway, Snycerski, Pradhan, \& Huitema, 2019; Perone, 2019; Tincani \& Travers, 2019) Fixsen and Blasé (this issue) show the cumulative power of replication and lacks thereof in building not just an "intervention" but an organization that thrives, whereas most of the other innovative solutions to social problems hatched in the 1960s are less well-remembered than "Brady Bunch" reruns on late night television. The TFM began with replications and extensions of then-current applied behavior analysis practices that were woven together to create a coherent therapeutic environment for delinquent youths. Learning from successful replications was the easy part, however, their honest and frank discussion of what was learned from replication failures (cf. Perone) are what make this article most valuable.

Donald A. Hantula

hantula@temple.edu

1 Decision Lab, Department of Psychology, Temple University, Philadelphia, PA 19122, USA 


\section{Considering a Bigger Picture}

However, reasons for the TFM's longevity are not the only questions we should ask. We should also step back and consider what it says for and about behavior science and behavior analysis. What is the proper unit of analysis? What is the proper unit of observation? Where are the natural lines of fracture? Answers to these fundamental problems are not fixed, but are fluid and depend on such factors as the research question, intended outcome, and anticipated inferences to be drawn. Research methods textbooks, methodology papers, common practices, and "lab lore" can provide practical answers to these problems and prescriptions for "acceptable" answers; however, no custom should be regarded as unalterable. As Skinner (1979, p. 346) advised, "Regard no practice as immutable, change and be ready to change again. Accept no eternal verity. Experiment." The question, application, and inference drive methodological choices. Methodology serves science. Unfortunately, dogmatic decisions about design too often obscure avenues for advancement. Methods are tools, nothing more and nothing less. Tools can contribute to success and survival, but they can also lead to demise. Weick (1996) used the firefighter's rule for survival ("drop your tools") as an allegory to illustrate the dangers of clinging to the familiar in the face of change. When confronted with an advancing wildfire, firefighters should drop their tools and run. However, as Weick describes, holding on to cumbersome tools for too long and refusing to drop them when necessary can be deadly. Wieck's observation about dropping methodological tools when the wind changes direction was based in his critique of organizational research, but it is valid for behavior science research as well.

What would make for a proper unit of analysis in behavior science? Organisms can be viewed and analyzed as a collection of interdependent organs. Some scientists may study the organism as a whole, as do many behavior scientists, whereas others may focus on a particular organ. Most relevant and complementary to behavior science is neuroscience (Donahoe, 2017), which focuses on a single organ, the brain. Some neuroscientists may study the brain for its own sake; however, behavioral and cognitive neuroscientists study the brain to understand the behavior of the organism as a whole. Indeed, for the behavioral science community writ large, brain research is interesting and important to the extent that it says something about behavior (Abramson \& Wells, 2018; Brumley, Strain, Devine, \& Bozeman, 2018; Ortu \& Vaidya, 2017).

Likewise, organizations can be viewed and analyzed as a collection of interdependent organisms. In organizational behavior management (OBM), the majority of research focuses on performance of the individual employee (Gravina et al., 2018). Although there have been attempts to formally link individual employee performance to larger scale organizational performance, it is too often simply assumed that improving individual employee performance will increase organizational effectiveness. Mappings of employee-level behavior change to organization performance change remain rare. However, many models exist that can facilitate this analysis. The Luthans and Kreitner (1975) Behavior Management Triangle (organizational consequences/outcomes, performances, relevant worker behaviors), Rummler's (Rummler \& Brache, 1990) three levels of performance (job/performer, process, organizational), behavior systems analysis (Diener, McGee, \& Miguel, 2009; McGee \& Diener, 2010), and process improvement (Dagen \& Nazaruk, 2017; Hyten \& Ludwig, 2017; Kelley \& Gravina, 2018; Lebbon \& Sigurdsson, 2017; Ludwig, 2017a, 2017b) all provide 
frameworks for linking individual employee performance to larger-scale outcomes. Granted, this work can be challenging in that it requires work both within and between levels of analysis, but it is necessary to move beyond assertion and speculation to convincing demonstration.

Organizations are ubiquitous. Their influence is pervasive and powerful, although sometimes subtle. No one can get through a day without interacting with a wide variety of organizations because organizations are the way that organisms, especially human organisms, get things done. In many ways, organizations seem to exist as if they are organisms. Organizations are created (born), they grow, develop, and perish (Mawhinney, 1992). Much like organisms, an organization's life span is generally short, often less than the lifespan of a typical human organism. Organizations are also subject to the same selection pressures as organisms; a particularly compelling example is Hannan and Freeman's (1977) demonstration that the population ecology of organizations is nearly identical to the population ecology of deer in the wild.

The answer to questions about the proper unit of analysis and observation is - it depends. It depends on the questions asked, inferences to be drawn, and changes to be made. The answer depends on the unit of selection that is under investigation. Selectionism is a scalable system. Selection operates at the cellular, organic, organismic, organizational, and cultural levels. "The behavior of organizations" is more than a behavior-nerdy pun; it is also recognition that the natural world its inhabitants and the things they create are part of a selectionist system. The same principles that account for survival or demise operate at each level. When working in a selectionist system, we need not concoct new conjectures, theories, or explanatory principles to account for phenomena at different levels of analysis. Instead, we can remain rooted in a selectionist base and branch off from there as demanded by the particular level we are working within. In a scalable selectionist system questions about conditioning a single neuron are as important and valid as questions about an individual's learning or an organization's use of electricity. What is being selected is what matters.

\section{The Behavior of a Single Organization}

This issue's special section reviews 50 years of research on the TFM and explores implications for other large scale behavioral applications. As Fixsen and Blasé (this issue) explain, the TFM's longevity and success is a combination of research, application, management, fortune and continuous improvement. Three commentaries place TFM work in a larger context. Gravina and King bring level and unit of analysis issues to bear on the TFM and shows how the TFM's development holds lessons for OBM research and practice and how OBM can inform further development of the TFM, which after all is an organization. Levin et al. discuss how converging and diverging dissemination strategies and implementation of acceptance and commitment therapy (ACT) and the TFM inform one another. Pinkelman and Horner place the TFM within a larger context of designing supportive cultures and show how positive behavioral interventions and supports (PBIS) and the TFM are exemplary behavioral models for improving social systems. 


\section{The Behavior of Authors}

The remaining articles in this issue ask us to revisit assumptions about our science, its theoretical propositions, and its units of analysis. Burgos and Killeen call for rapprochement between behavior science and cognitive science, calling us to question our assumptions about the "divide" between "behavioral" and "mentalistic" accounts of behavior. Ortu and Cihon also push theoretical boundaries and bring selectionism to bear on a neuro-operant account of recognition memory. Baum takes up hearing and stimulus discrimination, asking "what does it mean to hear a sound?" Sosoa and dos Santos propose a unified account of impulsivity and self-control, melding operant theory with associative learning. Mason and Andrews continue the PoBS tradition of methodological innovation and introduce and describe a new metric, the stimulus control ratio equations (SCoRE) that should prove useful to researchers and practitioners alike who work in verbal behavior. Layng provides a very useful and comprehensive tutorial on understanding concept learning.

\section{Creativity at $\mathbf{5 0}$}

From the breadth and depth of the research and scholarship presented in this issue, it is clear that we have learned much in 50 years. It appears that a dogmatic doctrinaire insistence that the individual organism is the only legitimate unit of analysis may be a similar stumbling block that impedes applied behavior analysis from integrating both neuroscience (micro-level) and organizational effectiveness (macro-level) into its practices. Certainly every science and its application has boundaries and limits (St. Peter, 2017). These are necessary not only for definitional purposes, but paradoxically, for advancement and exploration. Creativity craves constraints. From art to music to science, probing boundaries and pushing against constraints often yields new insights. Constraints also help motivate creative work by attenuating the paralysis of choice and "blank white page syndrome" that can be so overwhelming it can stop work before it even begins. However, constraints can also choke creativity, especially when there are too many constraints for the wrong reasons. Where these lines of fracture between inspiring constraints and demoralizing shackles occur will remain a topic of exploration, debate, and creative solutions.

\section{A Sad Farewell}

As this issue was going to press we learned the sad news that pioneering behavior scientist Murray Sidman passed away. We are gratified that we were able to publish the Spring 2018 volume dedicated to his research, scholarship, and influence during his lifetime (Critchfield, Barnes-Holmes, \& Dougher, 2018; Hantula, 2018). Too often these tributes come too late.

Acknowledgments I thank Tom Critchfield, Dave Jarmolowicz, and Erin Rasmussen for their comments on this editorial. 


\section{References}

Abramson, C. I., \& Wells, H. (2018). An inconvenient truth: Some neglected issues in invertebrate learning. Perspectives on Behavior Science, 41(2), 395-416. https://doi.org/10.1007/s40614-018-00178-8.

Branch, M. N. (2019). The 'reproducibility crisis:' Might the methods used frequently in behavior-analysis research help? Perspectives on Behavior Science, 42(1), 77-89. https://doi.org/10.1007/s40614-0180158-5.

Brumley, M. R., Strain, M. M., Devine, N., \& Bozeman, A. L. (2018). The spinal cord, not to be forgotten: The final common path for development, training and recovery of motor function. Perspectives on Behavior Science, 41(2), 369-393. https://doi.org/10.1007/s40614-018-00177-9.

Critchfield, T. S., Barnes-Holmes, D., \& Dougher, M. J. (2018). Editorial: What Sidman did: Historical and contemporary significance of research on derived stimulus relations. Perspectives on Behavior Science, 41(1), 9-32. https://doi.org/10.1007/s40614-018-0154-9.

Dagen, J., \& Nazaruk, M. (2017). Commentary: Integrating behavioral science with process safety management. Journal of Organizational Behavior Management, 37(3-4), 332-338. https://doi.org/10.1080 /01608061.2017.1367749.

Diener, L. H., McGee, H. M., \& Miguel, C. F. (2009). An integrated approach for conducting a behavioral systems analysis. Journal of Organizational Behavior Management, 29(2), 108-135. https://doi. org/10.1080/01608060902874534.

Donahoe, J. W. (2017). Behavior analysis and neuroscience: Complementary disciplines. Journal of the Experimental Analysis of Behavior, 107(3), 301-320. https://doi.org/10.1002/jeab.251.

Gravina, N., Villacorta, J., Albert, K., Clark, R., Curry, S., \& Wilder, D. (2018). A literature review of organizational behavior management interventions in human service settings from 1990 to 2016. Journal of Organizational Behavior Management, 38(2-3), 191-224.

Hales, A. H., Wesselmann, E. D., \& Hilgard, J. (2019). Improving psychological science through transparency and openness: An overview. Perspectives on Behavior Science, 42(1), 13-31. https://doi.org/10.1007 /s40614-018-00186-8.

Hannan, M., \& Freeman, J. (1977). The population ecology of organizations. American Journal of Sociology, 82(5), 929-964.

Hantula, D. A. (2018). Behavior science emerges. Perspectives on Behavior Science, 41(1), 1-6. https://doi. org/10.1007/s40614-018-0163-8.

Hyten, C., \& Ludwig, T. D. (2017). Complacency in process safety: A behavior analysis toward prevention strategies. Journal of Organizational Behavior Management, 37(3-4), 240-260. https://doi.org/10.1080 /01608061.2017.1341860.

Kelley, D. P., III, \& Gravina, N. (2018). Every minute counts: Using process improvement and performance feedback to improve patient flow in an emergency department. Journal of Organizational Behavior Management, 38(2-3), 234-243. https://doi.org/10.1080/01608061.2017.1423150.

Laraway, S., Snycerski, S., Pradhan, S., \& Huitema, B. E. (2019). An overview of scientific reproducibility: Consideration of relevant issues for behavior science/analysis. Perspectives on Behavior Science, 42(1), 33-57. https://doi.org/10.1007/s40614-019-00193-3.

Lebbon, A. R., \& Sigurdsson, S. O. (2017). Behavioral perspectives on variability in human behavior as part of process safety. Journal of Organizational Behavior Management, 37(3-4), 261-282. https://doi. org/10.1080/01608061.2017.1340922.

Ludwig, T. D. (2017a). Process safety behavioral systems: Behaviors interlock in complex metacontingencies. Journal of Organizational Behavior Management, 37(3-4), 224-239. https://doi.org/10.1080 /01608061.2017.1340921.

Ludwig, T. D. (2017b). Process safety: Another opportunity to translate behavior analysis into evidence-based practices of grave societal value. Journal of Organizational Behavior Management, 37(3-4), 221-223. https://doi.org/10.1080/01608061.2017.1343702.

Luthans, F., \& Kreitner, R. (1975). Organizational behavior modification. Glenview, IL: Scott Foresman.

Mawhinney, T. C. (1992). Evolution of organizational cultures as selection by consequences: The Gaia hypothesis, metacontingencies, and organizational ecology. Journal of Organizational Behavior Management, 12(2), 1-26. https://doi.org/10.1300/J075v12n02_01.

McGee, H. M., \& Diener, L. H. (2010). Behavioral systems analysis in health and human services. Behavior Modification, 34(5), 415-442. https://doi.org/10.1177/0145445510383527.

Ortu, D., \& Vaidya, M. (2017). The challenges of integrating behavioral and neural data: Bridging and breaking boundaries across levels of analysis. The Behavior Analyst, 40(1), 209-224. https://doi. org/10.1007/s40614-016-0074-5. 
Perone, M. (2019). How I learned to stop worrying and love replication failures. Perspectives on Behavior Science, 42(1), 91-108. https://doi.org/10.1007/s40614-018-0153-x.

Rummler, G. A., \& Brache, A. P. (1990). Improving performance: How to manage the white space on the organization chart. San Francisco, CA: Jossey-Bass.

Skinner, B. F. (1979). The shaping of a behaviorist. New York, NY: Knopf.

St. Peter, C. C. (2017). Beyond basic or applied. The Behavior Analyst, 40(1), 193-196. https://doi. org/10.1007/s40614-017-0104-y.

Tincani, M., \& Travers, J. (2019). Replication research, publication bias, and applied behavior analysis. Perspectives on Behavior Science, 42(1), 59-75. https://doi.org/10.1007/s40614-019-00191-5.

Weick, K. E. (1996). Drop your tools: An allegory for organizational studies. Administrative Science Quarterly, 41, 301+.

Publisher's Note Springer Nature remains neutral with regard to jurisdictional claims in published maps and institutional affiliations. 